\title{
Problems and Countermeasures on the Development of Precision Agriculture in Heilongjiang Province
}

\author{
Jinbo Zhang ${ }^{1,2, *}$, Junfa Wang ${ }^{1}$, and Caihua $\mathrm{Li}^{1}$ \\ ${ }^{1}$ College of Mechanical Engineering, Jiamusi University, Jiamusi, \\ Heilongjiang Province, P.R. China 154007, \\ Tel.: +86-454-8721580 \\ zhangjinpo9872@sina.com \\ ${ }^{2}$ The Key Laboratory of Terrain-Machine Bionics Engineering (Ministry of Education), \\ Jilin University, Changchun Jilin Province, P.R. China 130025
}

\begin{abstract}
The present development of precision agriculture is at the lower stage in Heilongjiang province, but it has taken effect in aspects of demonstration and extension. However there are many problems in the technology research and application, such as technology development lags, the key techniques supporting lags, the lack of " $3 \mathrm{~S}$ " technology service for agricultural application with independent intellectual property, the whole poor production conditions caused by the limited resource and the man-land conflict, the lacks of the agricultural funds and the higher level scientific researchers, the application difficulties between technique equipments of the high-tech content and the low cultural level of rural human resources, the inconvenient using of multifunction agricultural equipments for the dispersed land and complex landform and so on.

The above problems have limited the development of precision agriculture seriously in Heilongiiang province. Therefore, we should take the effective ways as soon as possible, depend on the existing experiences, techniques and equipments, and put forward the development strategy in accordance with regional condition to speed up the development of precision agriculture. There are many concrete countermeasures such as using demonstration experiences and production research results at home and abroad, introducing technique idea and partial equipments technique to promote independent innovation, proceeding demonstration experiments in the area with suitable conditions to spread of the idea of "precision agriculture", supporting the sustainable development of agriculture by new techniques and new equipments, enhancing communication and cooperation between department and subject, emphasizing the research of application basis, increasing the related course of precision agriculture such as GPS, GIS, RS and sensor technique and so on in colleges and universities, especially in agricultural universities, enhancing the development and application of computer and internet in the agricultural field, and so on.
\end{abstract}

Keywords: precision agriculture, development countermeasures, demonstration experiments.

\footnotetext{
* Corresponding author.
} 


\section{Introduction}

Precision agriculture is an agricultural development strategy. It is an idea on agriculture sustainable development to introduce high technology in the agriculture such as information, artificial intelligence and so on, which can utilize resources fully, decrease unnecessary capital input, reduce environmental pollution and obtain most economic benefit, social benefit and environment benefit. In the past few years, precision agriculture had got further research and practice, and formed some concrete production model, which is worth learning in our agriculture production. But because of imbalances in our agriculture production, implementation of precision agriculture under all kinds of natural conditions has great differences. Therefore according to the development level in our agriculture, it is necessary to take the suitable measure to develop precision agriculture based on the actual situation in every area.

At present implementation of precision agriculture is precision farming in fact, which is an intensive cultivation technology introduced the high technology of modern information and agronomy-agriculture engineering technology in the agriculture to get high yield, high efficiency, high quality and low consumption. That is to say, according to the previously determined index, the input of corps, operation and decision are controlled precisely, which can realize low input and high production. The basic characteristics of precision agriculture is a comprehensive system engineering that involves the accurate seed engineering, the accurate fertilization technology, the accurate seeding technology, the accurate irrigation technology, the dynamic crop monitoring technology and so on. Therefore to develop precision agriculture will promote the agricultural and rural sustainable development, even the whole human society.

\section{Advantages of Developing Precision Agriculture in Heilongjiang Province}

Heilongjiang province is an important commodity grain and soybean bases of china with its rich resources. Agricultural infrastructure construction has get the bigger achievement in Heilongjiang province, which has great potential market and wide development prospects. The advantages of developing precision agriculture in Heilongjiang province are, 1. regional superiority. Heilongjiang province has a flat and wide terrain with a large area of plain hinterland such as Sanjiang plain, Songnen plain and so on, which is convenient to form scale management and to work with the large modern farm implements. 2. talent superiority. Labor resources are abundant in Heilongjiang province. Research strength and the proportion of scientific and technical personnel have come out top in china. It is easy to get advanced talents. 3. technical superiority. Scientific and technical personnel have been begun to explore precision agriculture technology appropriately in Heilongjiang province based on introducing advanced technology and farm implements at home and abroad. Technology department of many university and local farms have researched deeply on precision drilling technology, variable fertilization technology, accurate irrigation technology and measuring-soil and formula technology, and also has get a lot of research results. 4. hardware superiority. Many farms such as Jiangsanjiang farm, Youyi 
farm and so on in Heilongjiang province, had been introduced advanced cultivation machinery and equipments, which had laid a hardware foundation and provided a supporting platform for extending and researching on precision agriculture. The above cases are the advantages of developing precision agriculture in Heilongjiang province.

\section{Exiting Problems of Developing Precision Agriculture In Heilongjiang Province}

The development of most agriculture still depends on natural conditions, the scale of famers is small and dispersed, and the area of per capita cultivated land is small in Heilongiiang province. Experiences on technology, production, and management are lack. The existing problems of developing precision agriculture are that, 1. Agricultural mechanization is at lower level. Agricultural infrastructure construction is relatively weak, and the degree of agricultural mechanization can't adapt to the development demand. Except for the large and middle farms, other farms have a low degree of agricultural mechanization, which can't meet the development of precision agriculture. 2. The development of agricultural informatization is slower. Infrastructure construction of information technology is relatively poor and need to strengthen. 3. Agricultural talents and famers' quality still need to improve. At present, the staff who is engaged in developing precision agriculture know only business not technology or know only technology not business. The comprehensive staff who knew technology and business are less. Farmer's education level is generally lower. Most of farmers don't know what precision agriculture is and how to develop it. They have not recognized the necessity and urgency of developing precision agriculture, and can't accept the previous high input. 4. Capital is lack. Precision agriculture is the capital intensive agriculture. In recent years, the main office of state farms and local governments at all levels increased the agricultural input, but the capital supporting for developing precision agriculture is far from enough. Specifically speaking, agricultural input is less, technology input is low, external capital input is small, the income per capita is low, and the capital for developing precision agriculture is lack seriously. 5. Technology and equipment of the independent development and independent innovation are less. Up to now, the new technology and new equipment of the independent development and independent innovation are less in Heilongjiang province, even the whole china. Some advanced tillage machinery and equipments are introduced from foreign countries, and the software for agricultural information and data processing is absent. The above questions are the "bottleneck" of developing precision agriculture in Heilongjiang province. It is a key to resolve the above questions for developing and extending precision agriculture.

\section{Countermeasures of Developing Precision Agriculture in Heilongjiang Province}

According to the advantages and existing problems of developing precision agriculture in Heilongjiang province and actual conditions, countermeasures of developing precision agriculture with Heilongjiang characteristics are as follow: 1. to improve 
emphatically mechanization level of the region suitable for developing precision agriculture during the follow years. The support dynamics of capital and technology should strength. To encourage farmers updates the existing small-sized or high-energy agricultural machinery and equipments. Country may provide favorable policy to the conditional area and increase the subsidy of buying advanced farm implements, which will lay a foundation for later developing and extending precision agriculture. 2 . to strengthen the infrastructure construction of agricultural informatization. At present, most of farmers in Heilongjiang province learn of information by looking others, by television, by broadcast and by newspaper. Few people know the agricultural information by related website. From the point of view of modern agriculture, it is necessary to establish agricultural information network and ensure the information channel. There are many agricultural information websites like Heilongjiang Information Port, and they had given full play of the important role. Strengthening the infrastructure construction of agricultural informatization is to establish a system of omnidirectional agricultural resources and information network in a large range, to promote informatization of agriculture production, to pay attention to the agricultural basic information and agricultural expert's knowledge acquisition, to provide accurate timely effective information service for agricultural decision department, agricultural enterprises and farmer, to establish some demonstration area of agricultural information, then to promote the process of agricultural informatization and information technology industrialization, to track the development trend of agricultural informatization at home and abroad, to make research and experiment further the international and domestic advanced technique, to fend to line with international practice on technology research of agricultural informatization and application ability, and to set up a high-quality and multi-level talent team in a short time. 3. to emphasize the cultivation of talents and improve farmer's quality. Precision agriculture needs some agricultural production managers with higher technology culture quality, with the ability of skilled operating computer and intelligent mechanical equipment, and with abundant agricultural technology knowledge. On the basis of actual situation in Heilongjiang province, scientific and technical personnel should have the professional technique training. At the same time, it is necessary and essential to attract the studying abroad personnel and related technology talents, even to choose some good technology personnel to study the most advanced technology of precision agriculture at abroad. Farmer's agriculture knowledge should improve synthetically, especially should enhance the understanding of precision agriculture and make them recognize the necessity and urgency of developing precision agriculture. 4. to establish some demonstration area of precision agriculture. Extending precision agriculture massively needs plenty of capital supporting. Therefore, in view of the actual situation, demonstration area of precision agriculture should be established from good rural area or farm, and research and application of agricultural high technology should be enhanced. Government and related departments should support for capital. At the same time, demonstration area also may absorb the capital at home and abroad with applicable ways such as shareholding and cooperation. The scientific and technical personnel's treatment should increase. As a role of template and demonstration, demonstration area can drive other area so as to achieve the goal of extending and popularizing of advanced technology. 5. to research the technological equipments with self-owned intellectual property right. At the same time, the advanced technology equipments at home and abroad would be introduced. 
In order to speed up the research process, the advanced foreign technology and equipments can be referenced, the independent research and innovation are carried out after mastering the key technology according to own practical situation. The achievement transformation must be accelerated and applied it to actual production as soon as possible. The operating mechanism of spreading and popularizing must be perfected, the scientific research achievements of precision agriculture should be extended propagandized with different forms, outstanding the important technology, mastering the key links, and carrying out the technological measures.

\section{Conclusion}

Apparatus The base and experience have provided a premise for speeding up the pace of advanced technology to transform traditional agriculture and achieve the development of precision agriculture in our province at this stage. At present, precision agriculture of our province still is at the exploration and research stage and does not have conditions of large scale and range extension. But leading development of precision agriculture will explore road and accumulate experience for development of precision agriculture and it can lay a foundation for the spreading and popularizing of precision agriculture of our country.

\section{Acknowledgements}

Author is grateful to professor Junfa,Wang associate professor Chuanhua Yang and lecturer Caihua Li for providing the support and help in this paper.

\section{References}

Yinsheng, Y., Xiufeng, A., Hongpeng, G.: The quantitative analysis of the feasibility for developing precision agriculture in jilin province. Journal of Agricultural Mechanization Research 5(2), 63-66 (2002)

Jianneng, C.: New intension of precision agriculture in the 21 st century and its development strategy in China. Journal of Fujian Agriculture Universigy (Social Science Edition) 6(1), 8-11 (2003)

Zhigang, X., Shuguang, Z., Yongqiang, Y., Yan, L.: The present situation and tendency of precision agriculture in China. Journal of Agricultural University of HeBei 26(5), 256-259 (2003)

Quanbao, Y., Hua, L., Zhongyang, H., Hongcheng, Z., Qigen, D., Ke, X.: Precision agriculture and its development countermeasure in China. Guizhou Agricultural Sciences 30(4), 58-59 (2002)

Lijiao, Y.: Consideration of several issues on developing precision agriculture in China. System Sciences and Comprehensive Studies In Agriculture 18(4), 273-276 (2002) 